\title{
PROBLEMS AND PROSPECTS OF RELIEVER AIRPORTS
}

\author{
Dr. David A. Newmyer \\ Stephen A. Mitchell and Jeffrey P. Smith \\ Southern Illinois University - Carbondale
}

\begin{abstract}
Introduction
In recent years, one of the most critical and misunderstood national airport funding and policy challenges has centered on the reliever airport - a growing and ever important general aviation facility normally located within the surrounding metropolitan city area.

Officially recognized in the mid 1960 's as a means of reducing delays at larger air carrier airports, reliever airports subsequently expanded and took on additional congressional support. However, even with the special funding considerations set forth in the Airport Improvement Program (AIP) Legislation of 1982, several formidable areas of legislative, administrative and operational deficiencies remain. Without appropriate changes to these consequences, a number of challenges may be insurmountable for many publicly and privately owned reliever airports in the years to come.

For relievers, the "legislative" part of the problem focuses on the evolving definition and criteria of relievers under changing aviation laws and re-authorization acts. The "administrative" inadequacies pertain to the level of funding available for relievers during the former Airport Development Aid Program (ADAP) Legislation and continued under the present AIP Legislation. The "operational" dilemma concerns an expressed need for airport expansion as a result of increasing levels of aircraft activity amid the complex operating constraints of their own metropolitan service area. These three areas (legislative, administrative and operational) are the focus of this article and are reviewed as part of a survey conducted in December 1989 of 110 reliever airports (mainly in the Chicago, New York, San Francisco, Los Angeles and Phoenix areas) in which airport manager's were asked key "reliever" airport issues.
\end{abstract}

\section{Role of Reliever Airports}

Essentially, a reliever airport's primary benefit is to allow greater capacity to one or more commercial airports (generally air carrier airports) while serving as a gateway for general aviation aircraft into metropolitan districts. Since their establishment, not only has their functional role been redefined, but the airport itself is the focus of increasing activity for which new standards and criteria have been developed (particularly at the state and regional planning level). Today, reliever airports appear to be facing more than operational changes; they are also challenged with many of the same political, economic and environmental considerations facing the primary airports that they are designated by the Federal Aviation Administration (FAA) to relieve.

\section{Evolution of the Reliever Airport Definition}

When viewed from the perspective of its definition, the overall contribution, significance and application of the reliever airport's role has changed significantly without a corresponding response in 
legislative, administrative and operational action. The changing role of relievers during the last ten years and the emphasis placed on their specific purpose has demanded an alteration of the original intent to include new ways of identifying general aviation airports as relievers. Although the reliever category did not change much in name from the 1982 legislation, the definition of relievers was broadened - so much in fact that it now allows for the inclusion of a number of additional general aviation airports which provide relief, but were previously not able to meet the earlier reliever criteria. This issue singularly raises the question of how relievers will grow in a controlled and equitable manner within the national airport system.

To describe only the current definition of relievers would be unjust without a comparison made to the historical progression of its original definition and established criteria. This following section traces the major historical reliever definitions used by the FAA and then contrasts them with the present definition supplied by the National Plan of Integrated Airport Systems, 1990 (NPIAS).

\section{Reliever Airport Definitions and Criteria}

\section{National Airport Plan Fiscal Years 1962 - 1966 (April. 1961)}

"Large and medium hubs need separate general aviation airports because of the very great air carrier activity and the excessive time it takes to get to an air carrier airport from many parts of a metropolitan area. Important segments of general aviation tend to desert air carrier airports when air carrier operations have reached 30,000 to 50,000 operations annually. In metropolitan areas, a neighborhood with 10 aircraft owners usually justifies an airport if no suitable one exists within 10 miles or 30 minutes driving time".

\section{National Airport System Plan Fiscal Years 1972-1992 (January. 1973)}

"Reliever airports, either existing or new, must meet all of the following:

a. It must primarily serve general aviation which is defined as an annual level of general aviation activity equal to at least 75 percent of the airport's total annual operations.

b. It must have reached a current activity level (or be officially forecast to reach such a level within the appropriate NASP period) of either:

1. 50 based aircraft, or

2. 25,000 annual itinerant operations, or

3. It must be located such that it clearly functions as a reliever to the major airport being relieved.

In order for a major airport to qualify for relief (relieved airport), it must meet simultaneously all of the following criteria:

a. It must be served by a certificated scheduled air carrier.

b. It must serve a recognized Standard Metropolitan Statistical Area (SMSA) having, or

forecast to have, either a population of 500,000 persons or a scheduled airline enplaned

passenger level of at least 250,000. 
c. It must be classed, or forecast as an S-2 (or 100,000 to 250,000 operations per year), or higher airport.

d. It must either:

1. Be operating, or officially be forecast to operate at 60 percent of its planned annual or peak hour capacity for the National Airport System Plan (NASP) period under consideration; or

2. Have operated at such a level in the past and have been previously provided with relief through designation of one or more reliever facilities qualified as indicated in this section.

\section{Airport and Airway Improvement Act of 1982 , Sec, 503, (a)18. (August 1982)}

"Reliever Airport means an airport designated by the secretary as having the function of relieving congestion at a commercial service airport and providing more general aviation access to the overall community".

\section{4. "Interim Criteria for Designating Reliever Airports." FAA Order 5090.3A National Plan of Integrated Airport Systems Criteria (January 25, 1983)}

Reliever airports shall meet the following criteria:

1. The reliever airport provides substantial capacity or instrument training relief, as evidence by:

a. A current activity level (or in the case of a new airport or airport that is slated for major improvement, a forecast activity level) of at least 50 based aircraft, or 25,000 annual itinerant operations, or 35,000 annual local operations, or;

b. The installation or proposed installation of a precision instrument landing system (ILS or MLS) when the FAA Regional Director has determined that the airport is a desirable location for instrument training activity.

2. The relieved airport:

a. Is a commercial service airport that serves a Standard Metropolitan Statistical Area (SMSA) with a population of at least 250,000 persons or at least 250,000 annual enplaned passengers, and -

b. Operates at 60 percent of its capacity, or operated at such a level before being a relieved airport, or is subject to restrictions that limit activity that would otherwise reach 60 percent of capacity.

Airports not meeting all of the above criteria may be included in the plan as reliever airports if they are so designated in a state, regional, or metropolitan system plan, and the FAA concurs in that portion of the plan.

As demonstrated by these definitions, the 1960's criteria for relievers was loosely defined in comparison to later reliever criteria. Conversely, the 1970's criteria was more detailed, providing several different qualifying guidelines for reliever airports in terms of the type and amount of activity as well as with the location of the airport within a Standard Metropolitan Statistical Area (SMSA). However, the 1980's criteria, in comparison to the 1970's criteria, has become less stringent. An example is the lowering of the SMSA size which qualifies for reliever status. Also, the 1980 's criteria has been changed to include discussion of relief from instrument operations based on training activity. 
Finally, the concluding qualifier on the 1980's criteria allows for the designation of reliever airports outside the national planning criteria under the contention that a state, regional and/or metropolitan area system plan calls for a reliever that has been concurred by means of FAA determination.

Furthermore, the 1990's definition of reliever airports has essentially remained unchanged from that of the 1980's. The National Plan of Integrated Airport Systems (NPIAS) 1990-1999 offers this basic definition. "Reliever airports are general aviation airports in metropolitan areas which are intended to reduce congestion at large commercial service airports by providing general aviation pilots with alternative landing areas, and providing more general aviation access to the overall community."

\section{A Status Report on the Reliever Airport System}

According to the National Plan of Integrated Airport System (NPIAS) 1990-1991, there are approximately 17,451 airports in the United States. Of the 3,385 airports included in the NPIAS, 285 (8\%) are reliever airports (National Plan of Integrated Airport Systems 1990-1999). It is clear that a fairly small number of reliever airports have been identified for special attention in the national airport planning system. However, without examining several individual reliever airport cases, it is difficult to understand why this category of airports should receive special attention as a consequence of its metropolitan status.

In reviewing reliever airport situations in fifteen metropolitan areas, several key areas of needs were identified which helped to consolidate and summarize the primary issues surrounding the current developments of these airports. These areas included the following:

1. System Preservation: Wherein the current system needs to be protected from airport closures (usually indicates that a large number of privately-owned relievers are in the area);

2. Existing System Development: Wherein one of the best options for obtaining new reliever capacity is the further development of the existing reliever system;

3. Public Relations: A key problem in these cases is the image of the reliever system in the minds of the area's citizenry. This public relations problem stands in the way of other options, especially existing system development; and

4. New Relief: This option means that new reliever airport sites need to be developed to supplement the existing reliever system. When this option is indicated, it usually means that such efforts are either underway or are at least possible.

\section{Historical Funding Levels for Relievers}

As the various definitions for relievers evolved, placing greater emphasis on its system-wide role, the amount of federal funding allocated to this category of airports generally increased. Funding authorizations for relievers from the Federal Aid to Airports Program (FAAP) hovered between $\$ 2$ to $\$ 5$ million per year during the 1960's (National Airport Program 1960-1979). In the first five years of the Airport Development Aid Program (ADAP), an average of just over $\$ 12$ million per year was spent on relievers, for a total of $\$ 61.5$ million from 1970 through 1975. During this period, there were three new reliever airports constructed and a total of 149 projects at 81 reliever airports. The $\$ 61.5$ million amounted to 4.7 percent of the total money spent under ADAP and 28.9 percent of the total money spent on general aviation airports during these years (AIP Annual Report of Accomplishments 1970-1975). 
With the change of reliever money classification in an amendment to the federal law from discretionary sources during 1970-1975 to specific allocations in 1976-1981, reliever airports saw even more improvement in their federal funding levels. The annual amount authorized to relievers during 1976 (plus the "transition quarter" in the change-over to new federal fiscal years) was $\$ 18.75$ million. While far better than the allocations during the 1960 's, this equated to $\$ 15$ million per year from 1977 through 1979 and $\$ 20$ million a year during 1980 and 1981 (AIP Annual Report of Accomplishments 19801990).

The Airport Improvement Program (AIP) formulated in 1982 mandated an even higher annual allocation for relievers. The law specified that a minimum of 10 percent of the basic authorization for all airports be spent on relievers (set aside under discretionary funds). This equated to $\$ 45$ million spent in FY 1982. In the first two years of AIP, the amount of money allocated to relievers exceeded the amounts allocated from 1970 through 1981. Approximately $\$ 138$ million was spent during FY 1990 , however by then, there were over 285 relievers included in the NPIAS; 82 more than in 1982 with an additional 71 planned (NPIAS 1990-1999).

The funding levels previously discussed suggest that there has been a definite increase in the apportionment of federal funds made available to a greater number of relievers. However, will it be enough as new relievers are added and existing relievers require greater capital development?

\section{Problems and Prospects}

In order to provide a better understanding of the challenges facing this category of airports, a questionnaire was distributed to a 157 reliever airports designated in the 1987 National Airport System Plan update. The relevance of these questions was to determine the most significant problems facing the respondent's airport in order to identify how individual concerns compare with system-wide reliever problems. In all, a total of 110 responses ( 70 percent) were received. Of these responses, 94 were from publicly-owned airports and 16 were from privately-owned airports. Overall, the surveyed airports had an average of 131,396 operations per year (106 to 110 respondents), 263 based aircraft (108 of 110 respondents) and 19 based jets (106 of 110 respondents).

The following six questions were asked of each respondent. Each question is summarized by the total number of responses and its corresponding percent table ranking.

Question \#1: "What is the greatest problem faced by your facility?" Each airport was limited to one response.

\begin{tabular}{lcc} 
Problem & Number & Percent \\
\hline Airspace/Traffic Congestion & 3 & 11.8 \\
Obstructions & 2 & 1.8 \\
Land Use Encroachment/Lack of Zoning & 14 & 12.7 \\
Needed Capital Improvements & 41 & 37.3 \\
Operating Costs & 14 & 12.7 \\
Community Opposition & 13 & 11.8 \\
Other & 11 & 10.0 \\
NoResponse & 2 & 1.8 \\
\hline Total Responses & 110 & 100 \\
\hline
\end{tabular}


Based on the 110 responses, an overwhelming 41 (37.3 percent) indicated that needed capital improvements is the most crucial problem. The next largest problem included a split between airport operating costs and land-use encroachment/lack of zoning, which was specified by 14 respondents respectively. Following closely behind are problems associated with community opposition and airspace/traffic congestion - indicated by 13 respondents each. As detected in the comment space provided for this question, many of the community opposition comments involved a lack of support for expansion purposes (runway extensions and additional land acquisition privileges).

Question *2: "To what extent do you feel it has been an advantage to be designated as a reliever airport in the National Plan of Integrated Airport Systems (NPIAS)?" The response to this question are:

\section{Problem}

Number Percent

\section{Large Advantage -}

attracted money our airport would have otherwise not received.

$64 \quad 58.2$

Moderate Advantage - financial help has been good but very difficult to obtain $\quad 24 \quad 21.8$

Small Advantage -

support has been barely enough to warrant special designation as a reliever $\begin{array}{llll}8 & 7.3\end{array}$

$\begin{array}{lrr}\text { None - it has not helped at all. } & 11 & 10.0\end{array}$

No Response

Total Responses

$110 \quad 100$

Nearly 80 percent of the respondents indicated that it has been either a moderate $(21.8 \%)$ or large (58.2\%) advantage to be designated as a reliever airport. On the negative side, only a combined 17.3 percent of the respondents felt it was of "small" or "no" advantage to be designated a reliever.

Question \#3: "What is the most important advantage of a reliever airport?" The tabulated responses to this question are as follows:

\begin{tabular}{lcc} 
Advantages & Number & Percent \\
\hline Geographic location near or in metropolitan area & 46 & 41.8 \\
High demand levels & 4 & 3.6 \\
Role in serving corporate users & 35 & 31.8 \\
Role in serving suburban areas & 6 & 5.5 \\
Other & 17 & 15.5 \\
No Response & 2 & 1.8 \\
\hline Total Responses & 110 & 100 \\
\hline
\end{tabular}

The responses to this question indicate that geographic location advantages (e.g. being located within or surrounding a metropolitan area) are the most important advantage of being a reliever airport. A similar response, the role of serving suburban areas, adds to this general trend. A response of secondary importance is the advantage of the role of serving corporate users - with 31.8 percent of the total responses. 
Question *4: Solutions to reliever problems were also covered in the questionnaire. Respondents were asked which type of the following environmentally related measures were in place at their airport.

Measures Responses

Curfews 7

Jet aircraft ban or limits

12

Noise monitoring

15

Land acquisition, easement acquisitions $\quad 46$

Others (abatement procedures, etc.) 24

$\begin{array}{ll}\text { None in use } & 41\end{array}$

No Response 0

Total Responses (*)

$\underline{145}$

$\left(^{*}\right)$ The total is greater than 94 because a number of airports have more than one measure in use.

Besides the $41(28 \%)$ who use no related environmental measures, a total of 46 of the 110 respondents used acquisition of land or easements as the primary measure to control environmental circumstances. The use of noise abatement procedures was reported by 24 of the 110 respondents. Next came noise monitoring use by 15 of the 110 respondents. In a corresponding survey question pertaining to the noise issue, respondents were asked if they thought government regulation would help improve the airport noise situation. The outcome was split with 57 responding yes, 52 no and 4 undecided. Many of those answering yes provided comments which clarified the need for a national general aviation noise policy to reduce airport liability for compatible land-use and zoning requirements. Next, following noise monitoring, a total of 12 of 110 respondents selected a ban or limit on jet aircraft operations and 7 of 110 reported selecting curfews.

Question \#5: When the respondents were asked "do you view such a metropolitan airport authority (or similar arrangement) an advantage," a 110 replied:

\begin{tabular}{lcc} 
Attitude & Number & Percent \\
\hline Clear advantage & 48 & 43.6 \\
Clear disadvantage & 25 & 22.7 \\
No change in our airport's situation & 29 & 26.4 \\
No Response & 8 & 7.3 \\
\hline Total Responses $\left(^{*}\right)$ & 110 & 100 \\
\hline
\end{tabular}

It seems that a significant percentage of (but not a majority of) respondents viewed metropolitan airport authorities as a clear advantage. The comments received pertaining to this question typically underscored the economic and political advantages associated with region and community control in solving local aviation issues. Others felt that such an authority was far removed from the obligations necessary for corporate and general aviation pilots and that an authority is too involved in multiagency politics. Another sizeable group (26\%) - many of whom may already be included in such authorities - saw no change in their airport's situation. Many of those in this category of response expressed the viewpoint that the primary airport would automatically receive the majority of financial support due to the funding priority. Additionally, they fell that regional political and 
economic representation was of little consideration to the smaller general aviation/reliever type airports.

Question \#6: Finally, respondents were asked if the 1987 AIP Legislation has been better for their airport than the old ADAP or AIP laws. Their responses were as follows:

\begin{tabular}{lcr} 
Attitude & Number & Percent \\
\hline It will provide significantly higher funding & 4 & 3.6 \\
No change - about the same & 35 & 31.8 \\
It will provide significantly lower funding & 6 & 5.5 \\
Not sure & 17 & 15.5 \\
No Response & 2 & 1.8 \\
\hline Total Responses $\left(^{*}\right)$ & 110 & 100 \\
\hline
\end{tabular}

In the two years since the 1987 AIP Legislation, 50 percent of the respondents felt that there had been no change in the way their airport was affected by the 1987 Law. While very few $(2.7 \%)$ maintained that the new law would provide significantly lower funding, nearly a third $(30.9 \%)$ were not sure how the new legislation affected them in terms of federal funding. This response may imply that many were still not fully aware of the funding implications and did not understand the genuine differences between the 1982 and 1987 AIP Legislation for reliever airports. Not many more than a narrow margin (10.9\%) agreed that they had experienced significantly higher funding advantages with the 1987 AIP Legislation.

\section{Concluding Remarks}

As evidence of this survey, it appears reliever airports are not only perceived by the respondents as achieving an important role within their own metropolitan area, but are also viewed as a significant contribution within the National Plan of Integrated Airport Systems (NPIAS). This is illustrated by 80 percent of the respondents who felt it was a large to moderate advantage to be included in the NPIAS.

In consideration of these benefits, there are also apparent disadvantages of being designated as a reliever airport - the most pressing of which coincides with the shortage of federal funds required for needed capital improvement projects. This survey further reveals that there are important opportunities for relievers in terms of attracting federal money and being able to carry out a defined and specific federal planning role. Nevertheless, it does not appear that the overall conditions faced by these airports will improve under current AIP Legislation.

While reliever airport problems are somewhat unified, their solutions are not. From this survey we see that there are clearly specific legislative, administrative, and operational areas which should be addressed in subsequent aviation legislation. This is especially true at the federal level so as to ensure a more clear, unambiguous stance which can be used system-wide for developing reliever airports. Overall, comments from the questionnaire pointed towards the need for better legislative guidance to uniformly help solve local issues that tend to be universal in nature (maintaining federal standards at general aviation airports, zoning requirements for airspace, environmental compliances and funding availability) but nevertheless require national attention, direction and solutions. 
With FAA forecasts projecting worsening traffic congestion at the nation's top commercial service airports, it is paramount that relievers do more than just compliment the primary and general aviation airports in their area. This challenge comes at a time when over half of our respondents feel that there have been no noticeable changes in AIP Legislation in comparison with prior AIP or ADAP Legislation. All of this falls under more progressive constraints which may well be the most painful attempt to expand without reconciliation of federal assistance.

When collectively constrained from participating in a manner that optimizes their ability to operate effectively, planning for the future is made more difficult when based on the decision galvanized from the 1987 AIP legislation. Overall, future legislation may need to more aggressively pursue NPIAS criteria and development with respect to the specific needs of the relievers themselves.

\section{Works Cited}

Annual Report of Accomplishments under the Airport Improvement Program U.S. Department of Transportation, Federal Aviation Administration (Issues 1970-1975)

National Plan of Integrated Airport Systems (NPIAS) 1990-1999 U.S. Department of Transportation, Federal Aviation Administration, U.S. Government Printing Office, Washington, D.C.

National Airport Program - Review of Federal Aid to Airports Program (FAAP), Federal Aviation Agency (1960-1970) 